\title{
Faculty Use of Established and Emerging Technologies in Higher Education: A Unified Theory of Acceptance and Use of Technology Perspective
}

\author{
Carmen C. Lewis ${ }^{1}$, Cherie E. Fretwell ${ }^{2}$, Jim Ryan ${ }^{3} \&$ James B. Parham ${ }^{4}$ \\ ${ }^{1}$ Troy University, Phenix City campus, USA \\ ${ }^{2}$ Troy University, Phenix City campus, USA \\ ${ }^{3}$ Troy University, Phenix City campus, USA \\ ${ }^{4}$ Troy University, Phenix City campus, USA \\ Correspondence: Carmen C. Lewis, Troy University, Phenix City campus, USA. E-mail: cclewis@troy.edu
}

Received: January 31, 2013

Accepted: March 17, 2013

Online Published: March 25, 2013

doi:10.5430/ijhe.v2n2p22

URL: http://dx.doi.org/10.5430/ijhe.v2n2p22

\begin{abstract}
Our effectiveness as instructors lies ultimately in how well our students can understand and apply the concepts we teach. In response to the growing importance of accountability in the educational process and the abundance of social networking technology and communication tools available for possible classroom use, this paper will use The Unified Theory of Acceptance and Use of Technology (UTAUT) to examine the adoption of established and emerging information technology in higher education classrooms. Hence, the goal of this paper is to test theoretical explanations from UTAUT in the context of higher education through the development of a set of hypotheses predicting the conditions under which classroom technology use is likely to emerge. Data collection occurred via an online survey. The instrument was sent to business faculty members teaching face-to-face classes at a southeastern university. Our findings suggest that in the context of instructors' use of technology for classroom purposes, the most important antecedents are performance expectancy, effort expectancy, social influence, and habit with more complex effects when gender is added as an interaction term. Results from this study will provide useful information on the frequency of use of technology, along with significant factors affecting its adoption in the classroom. Departmental leaders interested in the variations in individual faculty's level of inclination toward technological changes would find them particularly useful.
\end{abstract}

Keywords: Behavioral intention, Technology use, Technology acceptance

\section{Introduction}

Exceptional classroom instruction in higher education is not talked about nearly as much as the sports achievements for universities or even the research success within certain disciplines. In fact, most universities continue to reward research rather than teaching effectiveness for tenure-track faculty, and many students select universities based on the success and reputation of a football or basketball program. However, how well students understand and apply the concepts taught is the measure of instructor effectiveness, and should be one of the most important aspects of educational programs. As far back as 1955, conference remarks made by Lloyd Morey, then President of the University of Illinois, addressed improvement of instruction and the depth of responsibility that collegiate departments have to ensure quality of preparation of their members for academic teaching (1955). Active learning in higher education has been emphasized extensively over the past decade, and the "challenge is for lecturers to find ways of triggering and increasing student interest in the subject they are studying" (Tin, 2009). Without additional encouragement or rewards, many professors may focus most of their efforts on research, even with the tremendous increase in technology and digital media currently available that can actively engage learners.

The infusion of new technology has had a dramatic effect on the way that we send and receive information. Communication traditionally is based on a sender who encodes a message and sends it through a communication medium to a receiver, who then decodes the message. Historically, a typical classroom prior to the technology explosion would reflect the teacher as the sender, the course materials as the message, and the student as the receiver of the information. The face-to-face lecture format would represent the communication medium. Fast-forward to a 2012 higher education classroom and we find a generation of students who are extremely savvy about technology and media. They use digital media almost as if it were their first language in communicating with each other. Given the intensity of use of technology by students and the potential gap in technical expertise between students and professors, an even 
greater move toward interactive learning is needed in the higher education classroom in order to engage this techno-savvy generation in the instruction-learning process.

This paper reviews the factors and conditions that impact the extent of professor intent and use of established and emerging technologies in the higher education classroom. The Unified Theory of Acceptance and Use of Technology (UTAUT) to examine the adoption of information technology in higher education classrooms is used. This study is specific to the adoption of technology for use in face-to-face classroom instruction. Regarding the technologies in question, we seek to better understand, for instance, how often instructors gather materials for their classes from the Internet, allow students to use the Internet for assignments, and utilize online quizzes and exams. Additionally, we inquire the extent to which specific technologies such as Blackboard (course management system), Facebook, Twitter, and LinkedIn are used. As an important note, faculty use of e-mail will not be considered as use of technology in this study. Therefore, we address the following research question:

RQ: What are the factors that facilitate higher education professors' willingness to use classroom technologies?

The rest of this paper is presented as follows: First, the theoretical framework used to test intention and use of technology in the higher education classroom is described. A review of UTAUT follows, and then a set of hypotheses is developed predicting the conditions under which classroom technology use is likely to emerge. A research strategy and construct measures to test the hypotheses are presented, followed by the results from our analyses. The paper concludes with expected contributions, limitations, and opportunities for future research.

\section{Theoretical development}

In this section, technology acceptance and use literatures are reviewed to develop the research model and hypotheses.

\subsection{Unified Theory of Acceptance and Use of Technology}

We propose that the Unified Theory of Acceptance and Use of Technology (UTAUT) provides a comprehensive framework for predicting the conditions under which classroom technology use is likely to emerge. This theory initially integrated research on individual acceptance of technology into a unified theoretical model based on elements from eight previously established models (Venkatesh, Morris, Davis, \& Davis, 2003). The original UTAUT model consists of four antecedents to behavioral intention: performance expectancy, effort expectancy, social influence, and facilitating conditions (Venkatesh et al., 2003). Longitudinal field studies of employee technology acceptance revealed that "UTAUT explained about 70 percent of the variance in behavioral intention to use a technology and about 50 percent of the variance in technology use" (Venkatesh, L. Thong, \& Xu, 2012). UTAUT is considered a baseline model and has been used to study use of various technologies in many organizational settings. It has since been extended to include three additional predictors: hedonic motivation, price value, and habit (Venkatesh et al., 2012). Hence, it is typically referred to as UTAUT2. See Figure 1 for the complete theoretical framework that guides this research.

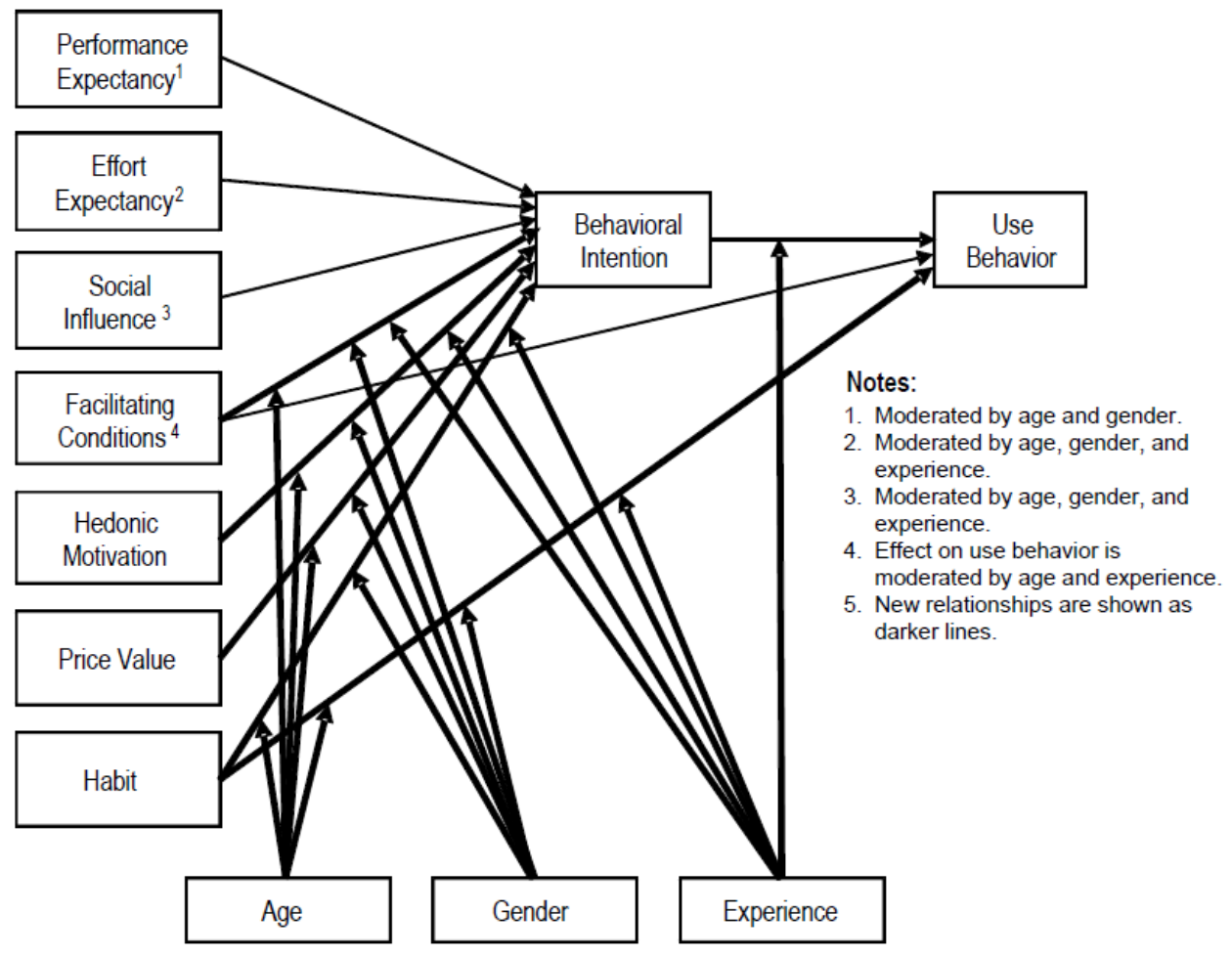

Figure 1. Theoretical Model: UTAUT2 (Venkatesh et al., 2012) 


\section{Research Model}

The research model, see Figure 2, uses Venkatesh's (2012) UTAUT2 constructs. There are two dependent variables of interest: current use of emerging classroom technologies and behavioral intention to use these technologies in the future. Hence, following the UTAUT2 model, we identify the antecedents of performance expectancy, effort expectancy, social influence, facilitating conditions, hedonic motivation, and habit as key constructs in our model, while extending it to the higher education context. Age and gender are also included and modeled as moderators as suggested by Information Systems (IS) adoption literature.

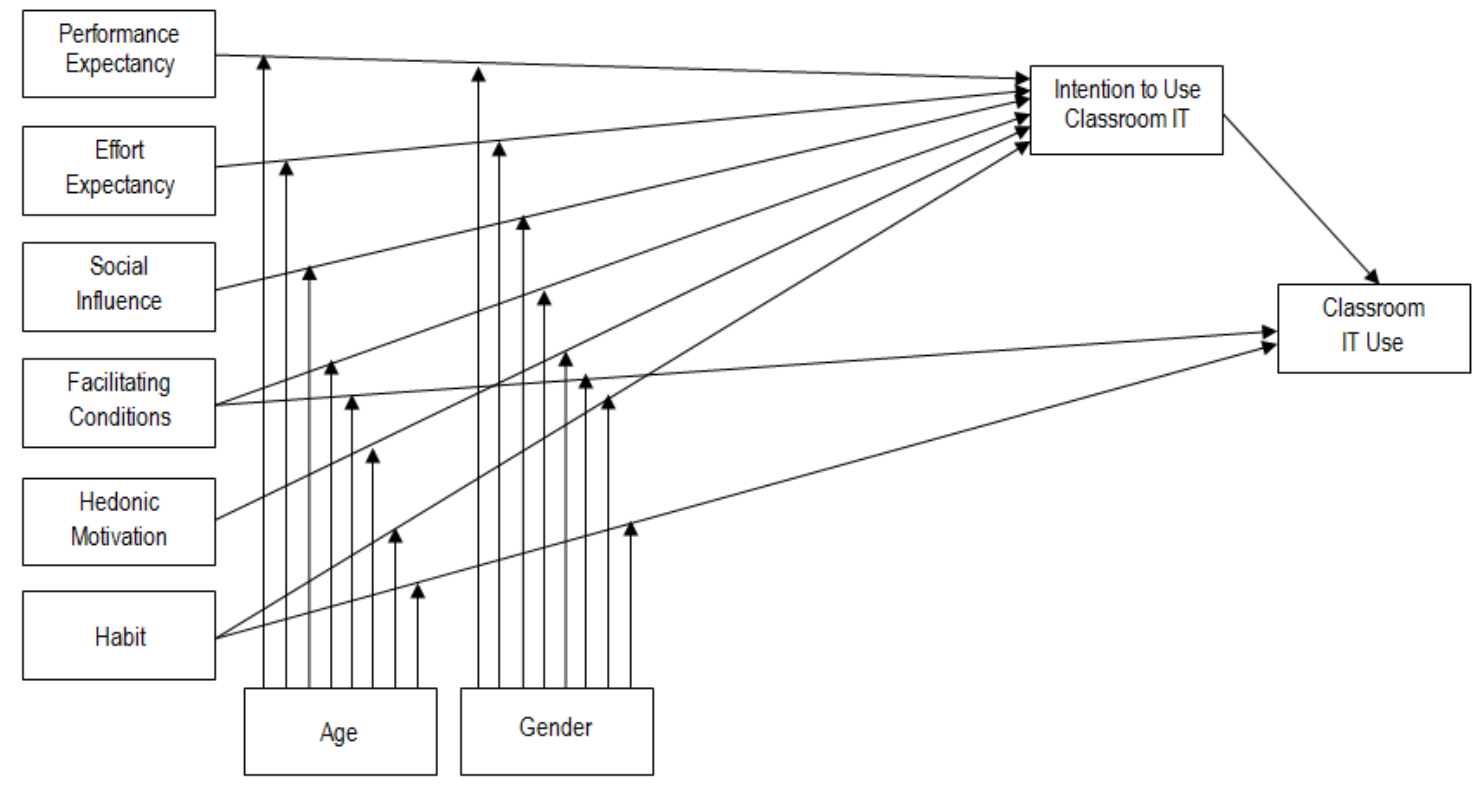

Figure 2. Research Model: UTAUT2 adapted from Venkatesh, et al. (2012)

\subsection{Performance expectancy}

Performance expectancy is defined as the degree to which an instructor believes existing and emerging technology will help improve job performance. Performance expectancy has been found to be the most significant factor used to explain behavioral intention, and has been found to be more significant for younger men (Venkatesh et al., 2003). Similarly, we propose the relationship between performance expectancy and behavioral intention and extend it to the higher education classroom setting. Prior research has suggested that performance expectancy has explanatory power concerning intention to use a technology in a college setting (Bandyopadhyay \& Fraccastoro, 2007). One such study examined the acceptance of virtual learning environments among faculty and students at universities in three Northern European countries: Sweden, Norway, and Lithuania (Keller, 2009). Keller (2009) found performance expectancy to vary among staff and students at the three universities. In addition to these findings, individual differences have been theorized to have both direct and indirect effects on technology use (Venkatesh et al., 2003). In our context, we model two individual differences as moderating effects: professors' age and gender. Research has shown gender differences in computer usage to increase as a person ages. In Europe specifically, "about twice the number of men than women above age 55 use a computer" (Seybert, 2007). Thus, we hypothesize that:

H1a: Performance expectancy will positively influence intention to use classroom technology.

H1b: Performance expectancy will positively influence classroom technology use.

H1c: Age and gender will moderate the effect of performance expectancy on behavioral intention, such that the effect will be stronger among younger male instructors.

\subsection{Effort expectancy}

Effort expectancy is defined as the degree to which faculty perceive technology use to be effort free. It is predicted by technology characteristics, such as social presence, immediacy, and concurrency, and individual and group characteristics, such as collaboration technology experience, computer self-efficacy, and familiarity with others (Brown, Dennis, \& Venkatesh, 2010). UTAUT2 models effort expectancy as a significant predictor of intention to use a technology. Therefore, the more effort that is perceived for technology use, the less likely individuals will intend to use it (Venkatesh et al., 2003). It has been found to be particularly effective in predicting use of personal technologies 
(Venkatesh \& Bala, 2008). Over 50\% of the users of Facebook access the site through their personal, mobile devices (Sengupta, 2012). Thus, we anticipate effort expectancy to be identified as an especially important predictor in the context of instructors' intention to use technology to enhance classroom learning. Thus, we hypothesize that:

H2a: Effort expectancy will positively influence intention to use classroom technology.

H2b: Effort expectancy will positively influence classroom technology use.

H2c: Age and gender will moderate the effect of effort expectancy on behavioral intention, such that the effect will be stronger among younger female instructors.

\subsection{Social influence}

Social influence is defined as the degree to which faculty members perceive that important individuals expect them to use the technology. Social influence's prediction ability of user intention has been less clear than performance expectancy and effort expectancy (Brown et al., 2010). However, it has been found to have more importance when users have less involvementwith a technology (Venkatesh \& Davis, 2000; Venkatesh \& Morris, 2000; Venkatesh et al., 2003). We expect social influence to play a larger role in predicting intention to use technology if a faculty member's supervisor uses the technology. Such supervisors would include a department chair or dean. Accordingly, we hypothesize that:

H3a: Social influence will positively affect intention to use classroom technology.

H3b: Social influence will positively affect classroom technology use.

H3c: Age and gender will moderate the effect of social influence on behavioral intention, such that the effect will be stronger among older female instructors.

\subsection{Facilitating conditions}

Facilitating conditions are defined as the extent to which a faculty member believes the college and technical infrastructure support use of the system. These conditions can be considered as "objective factors in the environment that observers agree make an act easy to accomplish" and are theorized to have a direct effect on intention and use of IS (Venkatesh et al., 2003). People generally seek assistance when trying something new, especially when the task involves innovative uses of technology. In situations where the facilitating conditions are inadequate, they may "act as an inhibitor" (Venkatesh, Thong, Chan, Hu, \& Brown, 2011) and individuals may exhibit negative attitudes toward the situation. On the other hand, if adequate resources are available, "individuals may be more likely to form positive attitudes as there are fewer reasons not to engage in the behavior" (Venkatesh et al., 2011). In our study, the construct facilitating conditions represents the support that one could expect in the university setting studied. However, similar to social influence, the explanatory power of this construct is also in question. Thus, we hypothesize that:

H4a: Facilitating conditions will positively influence intention to use classroom technology.

H4b: Facilitating conditions will positively influence classroom technology use.

H4c: Age and gender will moderate the effect of facilitating conditions on behavioral intention, such that the effect will be stronger among older female instructors.

\subsection{Hedonic motivation}

UTAUT2, a recent extension by Venkatesh of UTAUT to study acceptance and use of technology in a consumer context, presented three additional constructs: hedonic motivation, price value, and experience and habit (Venkatesh et al., 2012). They define hedonic motivation as the fun or pleasure derived from using a technology. Hedonic motivation has been found to influence technology acceptance and was used as a predictor of consumers' behavioral intention to use a technology (Brown \& Venkatesh, 2005). Another study regarding hedonic motivation found that enjoyment of the technology was a consistent and strong predictor of user acceptance (Childers, Carr, Peck, \& Carson, 2001). Thus, we hypothesize that:

H5a: Hedonic motivation will positively influence intention to use classroom technology.

H5b: Hedonic motivation will positively influence classroom technology use.

H5c: Age and gender will moderate the effect of hedonic motivation on behavioral intention, such that the effect will be stronger among younger male instructors. 


\subsection{Habit}

Prior use has been found to be a strong predictor of habit (Kim \& Malhotra, 2005; Limayem, Hirt, \& Cheung, 2007). Additionally, habit can be viewed as "a perceptual construct that reflects the results of prior experiences" (Venkatesh et al., 2012). Habit can be defined in the context of using technology and IS as "the extent to which people tend to perform behaviors (use IS) automatically because of learning" (Limayem et al., 2007). The importance of habit as a construct in a study of this type is that behavioral intention tends to decrease in terms of determining behavior as the particular behavior in question becomes more of a habit. Past research on habit "maintains that the automaticity of behavior lessens the need to access intention" (Limayem et al., 2007). Over an extended time period, continued use of technology "becomes habitual, which means that well-learned action sequences may be activated by environmental cues and then repeated without conscious intention" (Bandyopadhyay \& Fraccastoro, 2007). Thus, we hypothesize that:

H6a: Habit will positively influence intention to use classroom technology.

H6b: Habit will positively influence classroom technology use.

H6c: Age and gender will moderate the effect of habit on behavioral intention, such that the effect will be stronger for older male instructors.

\subsection{Behavioral intention}

Previous studies describe behavioral intention as a "function of both attitudes and subjective norms about the target behavior, predicting actual behavior" (Pickett et al. , 2012). The relative strength of a person's commitment to engage in a particular behavior can be assessed by behavioral intention. In a study extending Azjen's Theory of Planned Behavior (TPB) to eating disorders and body satisfaction, intentions were found to significantly predict behavior, consistent with past literature and Azjen's work (Pickett et al. , 2012). Behavioral change literature often reflects the role of outcomes in determining how likely the behavior will be sustained. In a study of reciprocal factors in behavior change, enjoyableness and success were found to be significantly related to behavior performance (Phillips \& Chapman, 2012). Their hypotheses were supported, suggesting that people who made a decision to initiate a particular behavior (in their case individuals made a decision to increase exercise) did so based on expected outcomes. We expect that instructors who begin to use emerging technologies in the classroom will find that it becomes enjoyable.

High fluency can be attained by repeated performance of a behavior (Phillips \& Chapman, 2012), and we expect that the more fluent instructors become at utilizing these emerging technologies, the more they will prefer to continue including these components as a part of their course preparation and classroom experience. Another behavioral change study regarding the transformation of preferences into values in terms of vegetarian eating practices showed that repetition of behavior led to increased enjoyment of the behavior (Rozin \& Markwith, 1997). Of course, individuals may intend to perform certain behaviors that they initially do not see as enjoyable, although they are viewed as positive behaviors. When they experience success subsequently with their behavior performance, their level of enjoyment from the behavior may increase. A study of behavior enjoyableness found that for individuals who are able to perform their goal behaviors successfully, the increase in enjoyableness and positiveness of the behaviors functions to continue their performance (Phillips \& Chapman, 2012).

\section{H7: Intention to use classroom technologies will have a significant positive influence on use behavior.}

\subsection{Use behavior}

A survey of research reveals that past behavior has a positive effect on future behavior, and some researchers assert that past usage is the only antecedent of future usage, even to the extent that it overshadows the impact of intention to use (Venkatesh \& Davis, 2000). They found that regardless of other control variables, the "past-behavior-future behavior relationship was found to be evident within a variety of contexts" (Venkatesh \& Davis, 2000). The results of a study of full time management faculty members from American colleges and universities with regard to faculty use of instructional technology found that most of those surveyed "clearly preferred using some form of technology, believed that their preferences enhanced their teaching effectiveness, and were comfortable with learning new technologies" (Peluchette \& Rust, 2005). Their findings demonstrated that faculty members had a positive view of learning new techniques and of using instructional technology.

Computers and other digital media have become a part of nearly every facet of life and work. Intel Corporation boasts that they are about "understanding and creating the next-wave applications, services, systems, and technology capabilities that will push the use of computing and communications technology further and touch the essence of what we hold most dear:ourselves, family, community and society" (D'Hooge, 2010). Although early technology was first 
part of life at work, "more and more technologies are transitioning from the workplace to the home and technologies are being designed specifically for household use" (Brown \& Venkatesh, 2005). Most middle-income households have had computers for the past decade, largely due to competitive pricing on computers, the widespread accessibility of the Internet, and a greater dependence on computers for work and school-related purposes (Yiing Jia \& Ching Szu, 2010). Families are finding that computers may be useful in household activities and may contribute to children's effectiveness in completing homework assignments and other academic and enrichment activities. In addition, many computer applications used in families are just for fun, and families even perceive an increase in prestige when they purchase a computer for home use (Venkatesh \& Brown, 2001).

We will measure the use of established technologies, i. e., Blackboard (or similar course management system), along with emerging technologies, in particular Facebook, Twitter, and LinkedIn, which at this time can be considered a novelty for classroom use. A study indicating that perceived novelty plays a significant role in the adoption of IT innovations framed the "concept of innovation novelty as not only an affective belief, but one that is positive in its orientation (fresh and exciting) rather than negative (scary and risky)" (Wells, Campbell, Valacich, \& Featherman, 2010). They define perceived novelty as "the degree to which a user perceives an innovation to be a new and exciting alternative to an existing technology" (Wells et al. , 2010). We feel our study will reveal that instructors perceive these emerging technologies as positive and useful in the classroom setting.

The use of information technology to support many activities associated with teaching and learning in higher education has expanded over the past decade to include much more electronic communication between faculty and students, and in particular, student-to-student and student-to-instructor interactions (Adria \& Rose, 2004).

UTAUT was developed in an organizational use setting, but the recent extension to study technology in a consumer use setting included price value as a construct. In the consumer use setting, consumers would usually incur the cost of purchase and use of technology, whereas employees in most organizations would not. Since our study is exclusively in an organizational setting, price value will not be used as a construct in our research model.

\section{9 Teaching styles}

Grasha (1996) identified five teaching styles: expert, formal authority, personal model, facilitator, and delegator. Expert instructors believe that they have knowledge and expertise that must be imparted to and understood by students. Formal authority instructors rely on the privileged role as instructor, developing learning goals and providing positive and negative feedback. Personal model instructors teach by example, guiding students to imitate their approach. Facilitator instructors are student-centered, intent on establishing an environment in which students can independently learn new concepts and take greater responsibility for their learning. The delegator instructor regards students as autonomous learners with access to the instructor as a resource (Grasha, 1996).

\section{Research Method}

\subsection{Measurement}

All of the scales used in the survey were adapted from prior research. The Appendix displays the measurement items. The performance expectancy, effort expectancy, social influence, facilitating conditions, hedonic motivation, habit, and behavioral intention scales utilized reflective items adapted from Venkatesh et al. (2012). These items were measured using a 7-point Likert scale, with the anchors "strongly disagree" and "strongly agree". Gender was coded using 1 and 2 where 2 represented females. Age was measured in years. Technology use was measured as a formative, composite index, representing frequency of classroom technology use. These items were adapted from Thomas (2011). To add to our descriptive statistics, we also captured the academic discipline of the professor. Hence, academic discipline was coded 1through 24 for the various teaching areas to describe differences among faculty teaching. Respondents were also asked to select the teaching style that most closely represented a self-assessment of their teaching styles from the following (adapted from Grasha's Teaching Styles, (1996): Expert, Formal Authority, Personal Model, Facilitator, or Delegator. A final analysis, considered post hoc, was also conducted relating to specific classroom technology use. That is, a list of four possible classroom technologies was provided: Blackboard (a popular course management system), Facebook, Twitter, and LinkedIn. These items were assessed on frequency of use on a 7-point Likert scale ranging from "never" to "always."These items were adapted from Venkatesh et al. (2012).

\subsection{Data Collection}

Our target population was U. S. instructors of face-to-face, higher-education classes. The data for our study are from 46 survey respondents representing $51 \%$ of the total numbers of surveys originally distributed to the population of interest. Subjects are full-time, face-to-face (traditional classroom) business faculty members at a Southeastern University in 
the United States. An e-mail with a link to the survey was sent out asking for participation in our study. As an incentive, respondents were entered into a drawing for three gift cards.

\section{Results}

Males represented $69 \%$ of the sample. The average age was 53 years old. Male professors described their teaching styles primarily as either the facilitator or the expert, while most females identified with the facilitator teaching style. The majority of our sample, $30 \%$, teaches management classes, with $15 \%$ teaching accounting, $15 \%$ information systems, $13 \%$ marketing, and $13 \%$ quantitative methods classes.

We first examined the measurement model to test its reliability and validity prior to running the structural model. In the preliminary analysis, confirmatory factor analysis (CFA) technique for data reduction was used with SPSS statistical software. With this technique, a model is specified and estimated, proposing a set of factors to account for the variance of some observed variables (Bagozzi, 1980). With CFA, the researcher seeks to determine whether the factor structure conforms to expectations on the basis of previous work or established theory. A seven-factor model was hypothesized based on à priori assumptions and theoretical findings.

Table 1. Loadings and Cross-Loadings

\begin{tabular}{|c|c|c|c|c|c|c|c|}
\hline Construct & & Factor 1 & Factor 2 & Factor 3 & Factor 4 & Factor 5 & Factor 6 \\
\hline & PE2 & .216 & .821 & .089 & .207 & .118 & .142 \\
\hline Performance & PE3 & .181 & .841 & .142 & .249 & .217 & .240 \\
\hline Expectancy & PE4 & .131 & .810 & .243 & .237 & .237 & .274 \\
\hline \multirow[t]{4}{*}{$($ Alpha $=.898)$} & PE5 & .141 & .831 & .052 & .289 & .075 & .218 \\
\hline & PE6 & .021 & .721 & .250 & .020 & -.187 & -.022 \\
\hline & EE1 & .830 & .079 & .057 & -.026 & .185 & -.062 \\
\hline & EE2 & .830 & .254 & .137 & .087 & .232 & .167 \\
\hline \multirow{4}{*}{$\begin{array}{l}\text { Effort Expectancy } \\
(\text { Alpha }=.923)\end{array}$} & EE3 & .861 & .291 & .138 & .130 & .108 & .034 \\
\hline & EE4 & .833 & .158 & .212 & .110 & .148 & -.012 \\
\hline & EE5 & .749 & -.060 & .210 & -.047 & -.325 & .311 \\
\hline & EE6 & .805 & -.016 & .217 & 198 & -.252 & .181 \\
\hline \multirow{4}{*}{$\begin{array}{l}\text { Social Influence } \\
(\text { Alpha = .956) }\end{array}$} & SI1 & .131 & .225 & .172 & .880 & .154 & .186 \\
\hline & SI2 & .074 & .263 & .187 & .883 & .139 & .175 \\
\hline & SI3 & .099 & .269 & 190 & .868 & .175 & .147 \\
\hline & HM1 & 288 & .322 & .708 & .171 & .248 & .221 \\
\hline \multirow{3}{*}{$\begin{array}{l}\text { Hedonic Motivation } \\
(\text { Alpha }=.922)\end{array}$} & HM3 & .206 & .062 & .857 & .228 & .106 & .026 \\
\hline & HM4 & .418 & .204 & .745 & .098 & .094 & .204 \\
\hline & HM5 & .167 & .398 & .768 & .180 & .176 & .098 \\
\hline \multirow{3}{*}{$\begin{array}{l}\text { Habit } \\
(\text { Alpha }=.830)\end{array}$} & HT2 & -.013 & -.010 & .527 & .139 & .657 & .193 \\
\hline & HT3 & -.028 & .128 & .172 & .381 & .727 & .178 \\
\hline & HT5 & .398 & .168 & .182 & .127 & .702 & .286 \\
\hline \multirow{3}{*}{$\begin{array}{l}\text { Behavioral Intention } \\
(\text { Alpha }=.930)\end{array}$} & BI1 & .084 & .336 & .135 & .228 & .297 & .785 \\
\hline & BI2 & .190 & .320 & .245 & .356 & .179 & .693 \\
\hline & BI3 & .246 & .453 & .224 & .344 & .318 & .606 \\
\hline
\end{tabular}

Notes: Extraction Method: Principal Component Analysis. Rotation Method: Varimax with Kaiser Normalization.

Table 1 presents the measurement model results, including reliability estimates and factor loadings and cross-loadings. The Cronbach alphas of multi-item scales modeled with reflective indicators ranged from .830 for habit to .956 for social influence, suggesting good reliability for the scales. The final loadings and cross-loadings table displays adequate convergent and discriminant validity. A few items had to be dropped from the initial solution due to low loadings and high cross-loadings. Unfortunately, the facilitating conditions scale did not hold together as hypothesized. It was removed altogether from the analysis due to a lack of consistency and validity, leaving six factors. The cumulative variance explained by the six factors was $83.95 \%$. The lowest loading in the final model was .606. Because technology use was modeled with formative instead of reflective indicators, it was excluded from the factor analysis. There were no obvious issues with multicollinearity as seen from the cross-loadings. 
Table 2. Means, Standard Deviations, and Correlations

\begin{tabular}{|c|c|c|c|c|c|c|c|c|c|c|c|}
\hline & Mean & SD & 1 & 2 & 3 & 4 & 5 & 6 & 7 & 8 & 9 \\
\hline 1.PE & 1.97 & 1.13 & 1 & & & & & & & & \\
\hline 2.EE & 2.68 & 1.36 & $.378^{* *}$ & 1 & & & & & & & \\
\hline 3.SI & 2.47 & 1.46 & $.541^{* *}$ & 294 & 1 & & & & & & \\
\hline 4.HM & 3.22 & 1.62 & $.527^{* *}$ & $.516^{* *}$ & $.491^{* *}$ & 1 & & & & & \\
\hline 5.HT & 3.37 & 1.75 & $.383^{*}$ & .280 & $.508^{* *}$ & $.553^{* *}$ & 1 & & & & \\
\hline 6.BI & 1.82 & 1.27 & $.652^{* *}$ & $.400^{* *}$ & $.641^{* *}$ & $.581^{* *}$ & $.605^{* *}$ & 1 & & & \\
\hline 7.TU & 3.43 & 1.00 & $-.467^{* *}$ & $-.291^{*}$ & $-.421^{* *}$ & $-.340^{*}$ & -.301 & $-.432^{* *}$ & 1 & & \\
\hline 8.GDR & 1.31 & .47 & .023 & -.174 & -.167 & -.047 & $-.328^{*}$ & -.113 & $.375^{*}$ & 1 & \\
\hline 9. $\mathrm{AGE}$ & 52.88 & 12.32 & $363^{*}$ & 197 & -.045 & .283 & .040 & .095 & -.003 & .172 & 1 \\
\hline
\end{tabular}

Notes: 1. PE: Performance Expectancy; EE: Effort Expectancy; SI: Social Influence;

HM: Hedonic Motivation; HT: Habit; BI: Behavioral Intention; TU: Technology Use; GDR: Gender; and AGE: Age.

2. ${ }^{*} \mathrm{p}<0.05 ; * * \mathrm{p}<0.01$ (two-tailed); all other correlations are insignificant.

Table 2 displays the means, standard deviations, and correlations. It is interesting to note that all direct effects of UTAUT2 variables were significantly correlated with intention to use classroom technology. Furthermore, apart from habit, they were also significantly correlated with technology use.

Table 3. Structural Model Results

\begin{tabular}{lcccc}
\hline \multicolumn{1}{c}{ DV:Behavioral Intention } & $\begin{array}{c}\text { Direct Effects } \\
\text { Only }\end{array}$ & $\begin{array}{c}\text { Direct Effects } \\
\text { and Interaction } \\
\text { Terms }\end{array}$ & $\begin{array}{c}\text { Direct } \\
\text { Effects Only }\end{array}$ & $\begin{array}{c}\text { Direct Effects } \\
\text { and Interaction } \\
\text { Terms }\end{array}$ \\
\hline R2 & DV:Behavioral Intention & \multicolumn{2}{c}{ DV:Technology Use } \\
Performance expectancy (PE) & .66 & .78 & .27 & .29 \\
Effort expectancy (EE) & $.39^{* *}$ & $.50^{* *}$ & $-.17^{* *}$ & $-.22^{* *}$ \\
Social influence (SI) & .09 & .08 & -.04 & -.04 \\
Hedonic motivation (HM) & $.20^{*}$ & $.28^{*}$ & -.09 & -.12 \\
Habit (HT) & .11 & -.75 & -.05 & .32 \\
GDR & $.28^{*}$ & $.30^{*}$ & -.15 & -.10 \\
AGE & .06 & -.02 & $.20^{*}$ & $.27^{*}$ \\
PE x AGE & -.10 & -.29 & -.12 & .06 \\
EE x AGE & & -.44 & & .20 \\
SI x AGE & & -.13 & & .06 \\
HM x AGE & & .10 & & -.04 \\
HT x AGE & & .84 & & -.37 \\
PE x GDR & & .25 & & -.11 \\
EE x GDR & & $-.19 *$ & & $.15^{* *}$ \\
SI x GDR & & $-.33^{* *}$ & & $-.10^{*}$ \\
HM x GDR & $.23^{*}$ & & -.04 \\
HT x GDR & & .09 & & -.10 \\
Behavioral Intention & & -.01 & & $-.44^{* *}$ \\
\hline N & & & $-.43^{* *}$ & \\
\hline
\end{tabular}

Notes: $* \mathrm{p}<0.05 ; * * \mathrm{p}<0.01$ (two-tailed)

To test the direct effects and interaction terms, we used Smart-PLS (partial least squares). Following Chin et al. (2003), PLS is capable of testing moderation and is useful for modeling indirect effects. The predictors were centered before creating interaction terms to avoid collinearity issues and to facilitate interpretation (Fürst \& Ghisletta, 2009). We ran two separate models to test direct effects versus direct with moderated effects. Table 3 reports the results of behavioral intention and classroom technology use as separate dependent variables. Behavioral intention was modeled as a mediating variable between the predictors and classroom technology use. When the interaction terms were not included in the model, there were significant effects for performance expectancy (PE), social influence (SI), and habit (HT) on behavioral intention (BI). In turn, BI, PE, and gender (GDR) had a significant impact on technology use (TU). When interaction terms were included, significant effects were found for performance expectancy $\mathrm{x}$ gender (PE $\mathrm{x}$ 
GDR), effort expectancy x gender (EE x GDR), and social influence $x$ gender (SI x GDR) on BI, and EE x GDR and SI $\mathrm{x}$ GDR on TU. The variability in BI explained by UTAUT without moderating terms was very good at 66 percent, increasing to 78 percent with interactions. Furthermore, the variability explained in technology use without and with the interactions was 27 percent and 29 percent, respectively.

Several of our hypotheses were supported. The first set of hypotheses pertained to the effects of performance expectancy on behavioral intention and technology use.H1a, which predicted that performance expectancy would positively influence intention to use classroom technology, was supported.As suggested in H1b, performance expectancy also had a positive impact on technology use. However, H1c was partially supported in that gender but not age, moderated the effect of performance expectancy on intention to use classroom technology. As predicted, this effect was stronger for male instructors. The second set of hypotheses was associated with the predictor, effort expectancy. Neither $\mathrm{H} 2 \mathrm{a}$ nor $\mathrm{H} 2 \mathrm{~b}$ were supported as there was not a direct relationship between effort expectancy and behavioral intention or classroom technology; however, H2c was partially supported. Specifically, upon adding the interaction term, gender, the effect became significant for both dependent variables, where effort expectancy had the strongest effect on male (not female) instructors. As such, this finding is in the opposite direction of what was predicted. Once again, age was not significant.H3a, which predicted that social influence would positively affect intention to use classroom technology, was supported; however, H3b did not hold up as the dependent variable, technology use, was not significantly related to social influence. Regarding the interaction terms in $\mathrm{H} 3 \mathrm{c}$, gender was a significant moderator but age was not, such that social influence was most important to female instructors. The set of hypotheses associated with $\mathrm{H} 4$ posited facilitating conditions would positively influence intention to use and actual use of classroom technologies; however, these hypotheses were not tested as the facilitating conditions scale did not hold together in the factor analysis. It was theorized in $\mathrm{H} 5$ that hedonic motivation would positively influence intention to use and actual use of classroom technology; however, this set of hypotheses was not supported by the data. H6a, which predicted that habit would positively influence intention to use classroom technology, was supported. However, its effects on actual use were not significant as predicted in H6b. Furthermore, as suggested in H6c, age and gender did not moderate this relationship. The last hypothesis was to make the connection between our two dependent variables. Specifically, H7 stated that intention to use classroom technologies would have a significant positive influence on use behavior. This hypothesis was supported.

Apart from our hypotheses, we also collected data on technology use, as it relates to four specific technologies: Blackboard, an established and popular course management system in higher education; and three more emerging social networking sites which can be used in the realm of higher education - Facebook, Twitter, and LinkedIn. These items were assessed based on frequency of use on a 7-point Likert scale ranging from "never" to "always". The results from Figure 3 show only $7 \%$ of the respondents never or rarely use Blackboard, with $48 \%$ stating they always use it. This is expected, considering that instructors using course management systems, such as Blackboard, derive great benefits through the ability to capture and archive data that can be utilized in grade appeals, program outcome assessments, comparison of course results across different groups and/or time periods, as well asvarious other uses by instructors and by administrators. However, these numbers diminish substantially when subjects were asked about the remaining three social networking sites. Only 5\% of our sample frequently uses Facebook for classroom purposes, while $100 \%$ and $98 \%$ never or rarely use Twitter and LinkedIn, respectively.

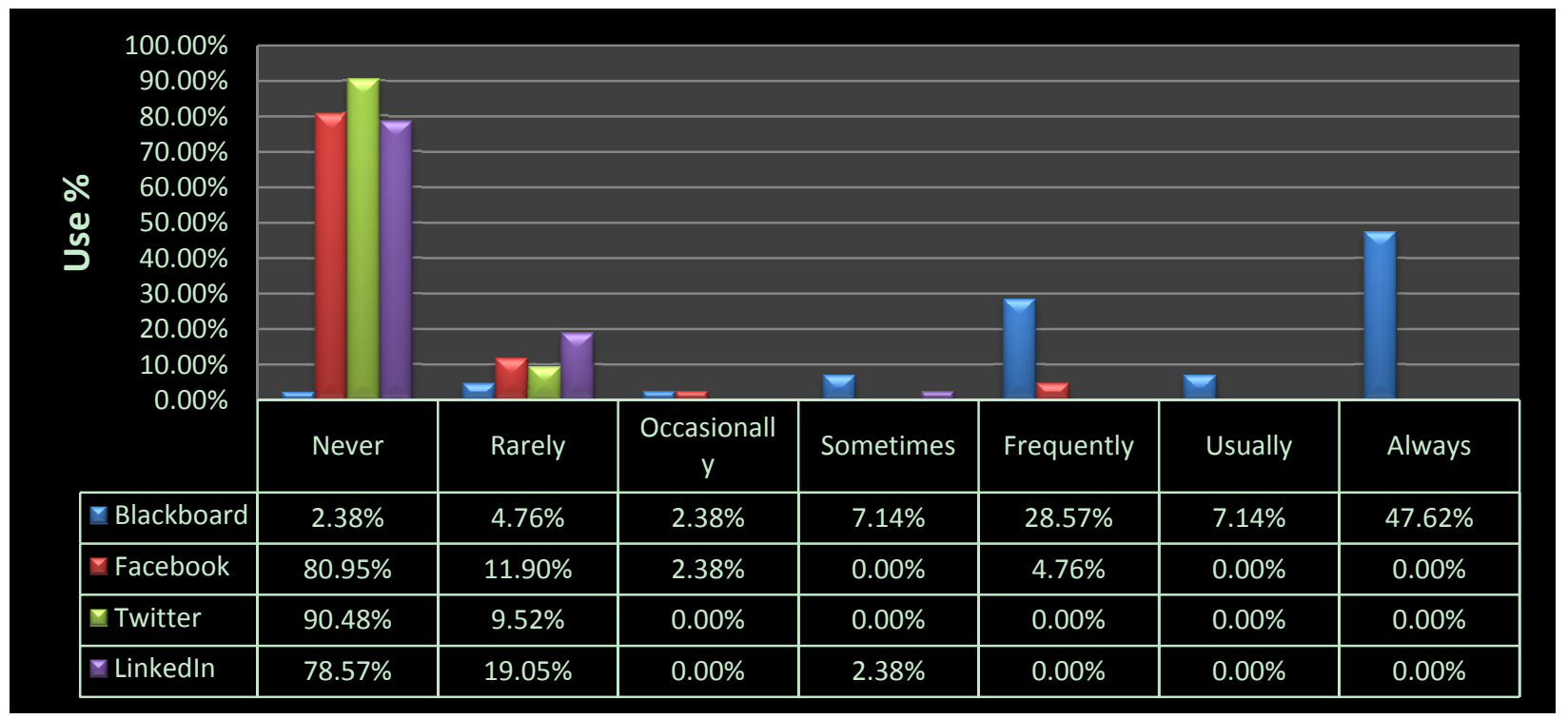

Figure 3. Specific Technology Use for Classroom Purposes 


\section{Discussion}

\subsection{Practical \& Theoretical Implications}

At a higher level, universities could reap benefits from instructors' moving beyond the historical lecture format of college teaching by engaging students in active learning through established and emerging technologies, including social networking technology and other communication tools. Social networks can provide new opportunities and innovative methods to connect with students digitally and provide a multi-sensory learning environment. As seen in Figure 4, the social network user penetration worldwide is trending upward. An astounding $25.8 \%$ of the world's population are projected to use a social networking site via any device at least once per month in 2014, and when we isolate the population to just Internet users, the number rises to $70.7 \%$ ("Facebook helps get one in five people worldwide socializing on online networks," 2012). Of the many social networking sites, Facebook is the leading reason, with over 1 billion users in 2013 ("Number of active users at Facebook over the years," 2012).

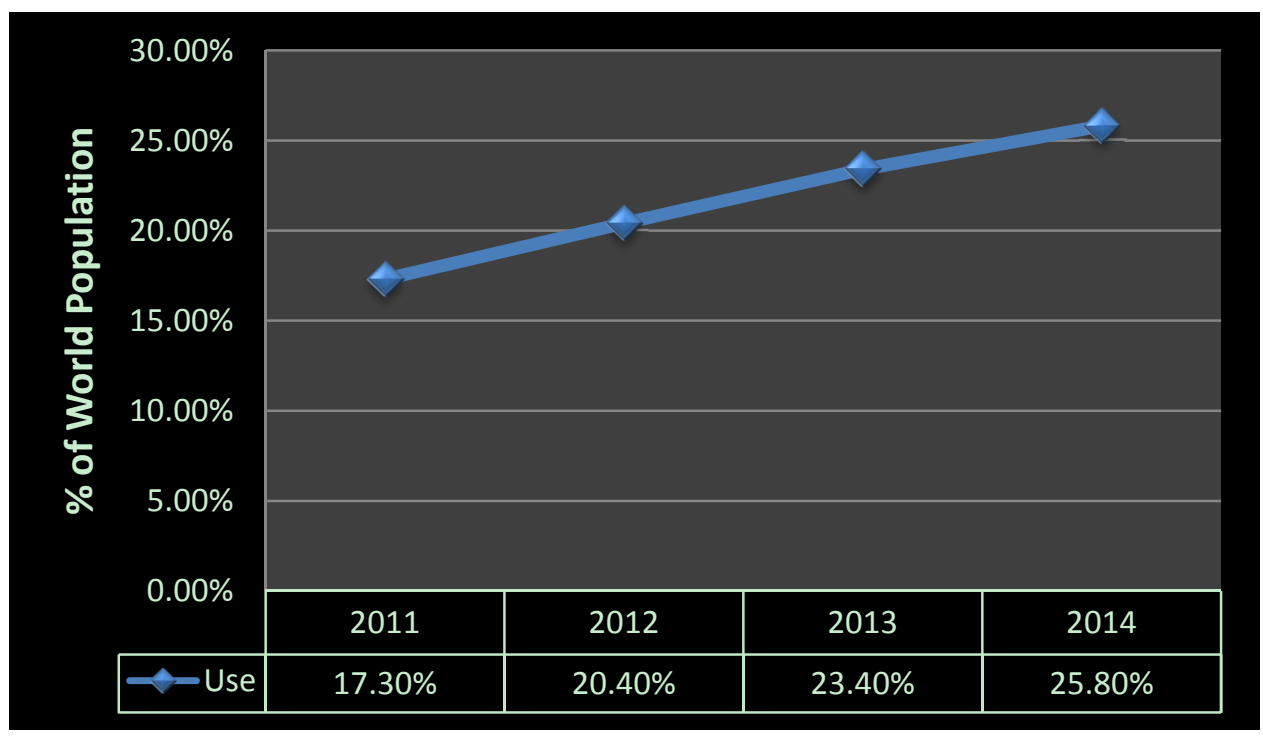

Figure 4. Social Network User Penetration Worldwide (Source: eMarketer, Feb 2012)

Despite these statistics, our findings show that professors are not utilizing these opportunities - on average $86 \%$ of faculty never use Facebook, Twitter, or LinkedIn for classroom purposes. An adjustment in the approach to class preparation and delivery methods by adding social networking technologies to compliment established course management systems, such as Blackboard, would enable instructors to take advantage of a media-rich environment to reinforce and strengthen the learning process. Our results show performance expectancy, effort expectancy, social influence, and habit play important roles in predicting intentions to use technology in the classroom. For the first two, the effect is even stronger for males, while social influence is stronger for females. That is to say, when male instructors perceive technology to be easy to use, effort free, and performance enhancing, then their intention to use it and actual use will increase. However, female instructors are more driven to use technology by social influence from people they perceive to be important.

Of these variables, social influence would be the one where school leaders could exert the most control. That is, professors' intention to use classroom technology and actual use may increase if their department chair and/or dean clearly champion its benefits. This effect appears to be even stronger for males, according to our results. Performance expectancy is the second variable that may also be enhanced by school leaders through conveyance of the usefulness and possible benefits of technologies, particularly as facilitators of computer-mediated communication. Most students now have applications associated with social networks downloaded to their cell phones. As such, many benefits could be derived from instructors tapping into this resource. For example, this would create a synchronous communication channel between the student and instructor allowing the latter to easily push classroom materials out to students, while providing the former ease of access.

\subsection{Limitations and Future Research}

Our first limitation relates to the exclusion of online instructors from our sample. Particularly, this study took a narrow focus, allowing it to generalize only to those instructors teaching face-to-face business classes. However, we created 
that boundary as a first attempt to increase our understanding of UTAUT2 in the higher education context of traditional classrooms. This study can be perceived as a directional one for further research, which presents an opportunity to expand the boundaries to include non-traditional, online instructors. Such additional research could also address the benefits of incorporating social networking technology into online instruction, in addition to better understanding the motivation to use it. As online instruction continues to grow in popularity among the tech-savvy student population, this knowledge would prove useful to instructors attempting to craft an interesting and relevant class. Departmental leaders would also benefit from this information through the recognition of factors affecting adoption, thereby lending motivation to encourage professors to advance beyond the sole use of typical course management systems. Further research is also needed to extend the framework to look at other teaching areas. As previously mentioned, our sample consisted solely of instructors in the college of business. Exploring other teaching areas would allow for comparisons across disciplines. Perhaps technology use and the significant factors that affect its use vary across different units in a university. Such questions could be examined with a more diverse sample. Along these lines, a further limitation associated with the current study is the size of the sample. Although we had a high response rate, only 46 surveys were completed. Furthermore, only $31 \%$ of the sample was female, which may not capture all relationships. However, PLS was specifically chosen as the analysis technique because of its robustness to reductions in sample size (Chin \& Newsted, 1999). Our desire is that through repetition studies, we can expand the sample to include more males and females from several disciplines.

The use of self-reported measures is a second limitation of this study. Although it is extremely common and accepted among adoption studies, the inclusion of objective measures would be preferable. Thus, we encourage researchers in this area to explore creating such measures to enhance the quality of these findings.

The final recommendation for future research is to extend the UTAUT2 framework to incorporate culture in the adoption of technology for use in classroom instruction. Globalization has led to people doing business and communicating far beyond their national or regional borders. Information technology is at the heart of these exchanges by enabling communication between people in different countries. Consequently, IS researchers have argued the importance of studying espoused national culture differences and their impact on these activities (Ives \& Jarvenpaa, 1991). In sum, we propose additional research is needed in order to further explore and understand the potential application of UTAUT2 in the higher education context across cultures.

\section{Conclusions}

In conclusion, much IS research has been focused on adoption of various technologies; however, in 2012 the UTAUT model was expanded and refined in the creation of UTAUT2. This created an exemplary opportunity to test the model in new contexts. To that end, this study found that in the context of instructors' use of technology, the most important antecedents are performance expectancy, effort expectancy, social influence, and habit with more complex effects when gender is added as an interaction term. Our study specifically indicated that the relationship between performance expectancy and effort expectancy on intention to use classroom IT was stronger for males, while the relationship between social influence and usage was stronger for females. This aligns with research suggesting men tend to be very task-oriented; therefore, performance expectancies linked with task accomplishment are likely to be more salient to men than women (Minton \& Schneider, 1980). Surprisingly, our findings show effort expectancy to have a stronger influence on men, not women (as predicted). Thus, ease of use of classroom technology would have a stronger impact on male professors. On the other hand, women are more responsive to social cues. "Women are socialized to behave prosocially, to cooperate, and to discourage discord" (Roberts, 1991). This, in turn, "leads women to be more responsive than men to the needs of others, and to accept the suggestions of others by acquiescing and agreeing" (Roberts, 1991). In a university setting, female professors may be more likely to succumb to pressure to use Blackboard or other social networking technology than men, particularly if promoted by their peers and supervisors.

\section{Acknowledgements}

The authors thank Caleb Walls (an undergraduate business student) for his efforts in creating the online survey for this paper. We also thank the associate editor and the two anonymous reviewers.

\section{References}

Adria, M., \& Rose, T. (2004). Technology, preprocessing, and resistance - A comparative case study of intensive classroom teaching. Journal of Education for Business, 80(1), 53-60. http://dx.doi.org/10.3200/JOEB.80.1.53-60

Bagozzi, R. P. (1980). Causal modeling in marketing. New York, NY: Wiley \& Sons.

Bandyopadhyay, K., \& Fraccastoro, K. A. (2007). The effect of culture on user acceptance on information technology. Communications of AIS, 2007(19), 522-543. 
Brown, S. A., Dennis, A. R., \& Venkatesh, V. (2010). Predicting collaboration technology use:Integrating technology adoption and collaboration research. Journal of Management Information Systems, 27(2), 9-53. http://dx.doi.org/10.2753/MIS0742-1222270201

Brown, S. A., \& Venkatesh, V. (2005). Model of adoption of technology in households:A baseline model test and extension incorporating household life cycle. MIS Quarterly, 29(3), 399-426.

Childers, T. L., Carr, C. L., Peck, J., \& Carson, S. (2001). Hedonic and utilitarian motivations for online retail shopping behavior. Journal of Retailing, 77(4), 421. http://dx.doi.org/10.1016/S0022-4359(01)00056-2

Chin, W. W., Marcolin, B. L., \& Newsted, P. R. (2003). A partial least squares latent variable modeling approach for measuring interaction effects:Results from a monte carlo simulation study and an electronic-mail emotion/adoption study. Information Systems Research, 14(2), 189-217. http://dx.doi.org/10.1287/isre.14.2.189.16018

Chin, W. W., \& Newsted, P. R. (1999). Structural equation modeling analysis with small samples using partial least squares. In R. Hoyle (Ed.), Statistical Strategies for Small Sample Research (pp. 307-341). Newbury Park, CA: Sage Publications.

D'Hooge, H. D. (2010). Essential computing:Simplifying and enriching our work and daily life. Intel Technology Journal, 14(1), 6-15.

Facebook helps get one in five people worldwide socializing on online networks. (2012). eMarketer. Retrieved from eMarketer website.

Fürst, G., \& Ghisletta, P. (2009). Statistical interaction between two continuous (latent) variables. Paper presented at the 11th Congress of the Swiss Psychological Society.

Grasha, A. F. (1996). Teaching with style:A practical guide to enhancing learning by understanding teaching and learning styles.

Ives, B., \& Jarvenpaa, S. L. (1991). Applications of global information technology:Key issues for management. MIS Quarterly, 15(1), 32-49. http://dx.doi.org/10.2307/249433

Keller, C. (2009). User acceptance of virtual learning environments:A case study from three north European universities. Communications of the Association for Information Systems, 25(38), 465-486.

Kim, S. S., \& Malhotra, N. K. (2005). A longitudinal model of continued IS use: An integrative view of four mechanisms underlying postadoption phenomena. Management Science, 51(5), 741-755. http://dx.doi.org/10.1287/mnsc.1040.0326

Limayem, M., Hirt, S. G., \& Cheung, C. M. K. (2007). How habit limits the predictive power of intention: The case of information systems continuance. MIS Quarterly, 31(4), 705-737.

Minton, H. L., \& Schneider, F. W. (1980). Differential Psychology. Prospect Heights, IL: Waveland Press.

Morey, L. (1955). Remarks before annual meeting of American Accounting Association. Accounting Review, 30(1).

Number of active users at Facebook over the years. (2012). [Online] Available: http://finance.yahoo.com/news/number-active-users-facebook-over-230449748.html

Peluchette, J. V., \& Rust, K. A. (2005). Technology use in the classroom: Preferences of management faculty members. Journal of Education for Business, 80(4), 200-205. http://dx.doi.org/10.3200/JOEB.80.4.200-205

Phillips, L. A., \& Chapman, G. B. (2012). Enjoyment and success: Reciprocal factors in behavior change. Journal of Applied Social Psychology, 42(4), 990-1009. http://dx.doi.org/10.1111/j.1559-1816.2011.00849.x

Pickett, L. L., Ginsburg, H. J., Mendez, R. V., Lim, D. E., Blankenship, K. R., Foster, L. E., . . Sheffield, S. B. (2012). Ajzen's theory of planned behavior as it relates to eating disorders and body satisfaction. North American Journal of Psychology, 14(2), 339-354.

Roberts, T.-A. (1991). Gender and the influence of evaluations on self-assessments in achievement settings. Psychological Bulletin, 109(2), 297. http://dx.doi.org/10.1037/0033-2909.109.2.297

Rozin, P., \& Markwith, M. (1997). Moralization and becoming a vegetarian:The transformation of preferences into values and the recruitment of disgust. Psychological Science (Wiley-Blackwell), 8(2), 67-73. http://dx.doi.org/10.1111/j.1467-9280.1997.tb00685.x 
Sengupta, S. (2012). Facebook's prospects may rest on trove of data, The New York Times. [Online] Available: http:/www.nytimes.com/2012/05/15/technology/facebook-needs-to-turn-data-trove-into-investor-gold.html?_r= 1

Seybert, H. (2007). Gender differences in the use of computers and the Internet. Eurostat, Statistics in focus, Catalogue Number KS-SF-07-119-EN-N.

Thomas, C. D. (2011). Factors affecting faculty use of technology-enhanced instruction at research universities. (Ph.D.), The University of Texas at Austin.

Tin, T. B. (2009). Features of the most interesting and the least interesting postgraduate secondlanguage acquisition lectures offered by three lecturers. Language and Education, 23(2), 117-135. http://dx.doi.org/10.1080/09500780802152770

Venkatesh, V., \& Bala, H. (2008). Technology acceptance model 3 and a research agenda on interventions. Decision Sciences, 39(2), 273-315. http://dx.doi.org/10.1111/j.1540-5915.2008.00192.x

Venkatesh, V., \& Brown, S. A. (2001). A longitudinal investigation of personal computers in homes:Adoption determinants and emerging challenges. MIS Quarterly, 25(1), 71-102. http://dx.doi.org/10.2307/3250959

Venkatesh, V., \& Davis, F. D. (2000). A theoretical extension of the technology acceptance model: Four longitudinal field studies. Management Science, 46(2), 186. http://dx.doi.org/10.1287/mnsc.46.2.186.11926

Venkatesh, V., L. Thong, J. Y., \& Xu, X. (2012). Consumer acceptance and use of information technolgy:Extending the unified theory of acceptance and use of technology. MIS Quarterly, 36(1), 157-178.

Venkatesh, V., \& Morris, M. G. (2000). Why don't men ever stop to ask for directions?Gender, social influence, and their role in technology acceptance and usage behavior. MIS Quarterly, 24(1), 115-139. http://dx.doi.org/10.2307/3250981

Venkatesh, V., Morris, M. G., Davis, G. B., \& Davis, F. D. (2003). User acceptance of information technology:Toward a unified view. MIS Quarterly, 27(3), 425-478.

Venkatesh, V., Thong, J. Y. L., Chan, F. K. Y., Hu, P. J.-H., \& Brown, S. A. (2011). Extending the two-stage information systems continuance model: incorporating UTAUT predictors and the role of context. Information Systems Journal, 21(6), 527-555. http://dx.doi.org/10.1111/j.1365-2575.2011.00373.x

Wells, J. D., Campbell, D. E., Valacich, J. S., \& Featherman, M. (2010). The effect of perceived novelty on the adoption of information technology innovations: A risk/reward perspective. Decision Sciences, 41(4), 813-843. http://dx.doi.org/10.1111/j.1540-5915.2010.00292.x

Yiing Jia, L., \& Ching Szu, F. (2010). Computer ownership and home usage: The case of Malaysia. International Journal of Consumer Studies, 34(1), 96-104. http://dx.doi.org/10.1111/j.1470-6431.2009.00849.x 